\title{
Solution Structure of Duplex DNA Containing a $\beta$-Carba-Fapy-dG Lesion
}

Mark Lukin, Tatiana Zaliznyak, Sivaprasad Attaluri, Francis Johnson and Carlos de los Santos*

Department of Pharmacological Sciences. Stony Brook University-School of Medicine. Stony Brook, NY, 11794-8651

\section{SUPPORTING INFORMATION}

Proton chemical shifts (Table 1S) on the $\beta$-cFapy-dG・dC duplex measured at 25 ${ }^{\circ} \mathrm{C}$. One dimensional proton spectrum of the $\beta$-cFapy-dG・dC duplex recorded in $100 \% \mathrm{D}_{2} \mathrm{O}$ buffer at $25{ }^{\circ} \mathrm{C}$ (Figure $1 \mathrm{~S}$ ), full 'finger print' region assignments on a 300 ms mixing time NOESY spectrum, recorded in $100 \% \mathrm{D}_{2} \mathrm{O}$ buffer at $25^{\circ} \mathrm{C}$ for the damaged (Figure 2SA) and undamaged (Figure 2SB) strands of the duplex, and expanded contour plot of the aromatic proton region on a $300 \mathrm{~ms}$ mixing time NOESY spectrum recorded in 100\% D2O buffer at $25 \stackrel{\circ}{\circ}$ (Figure 3S). Three-dimensional view of the twenty five Z- (Figure 4S) and E- (Figure 5S) $\beta$-cFapy-dG・dC duplex structures, and examples of water-mediated hydrogen bonds in the $\beta$-cFapy-dG・dC duplex (Figure $6 \mathrm{~S}$ ). $\mathrm{UV}_{260}$ melting curves for the $\beta$ cFapy-dG・dC and dG・dC duplexes (Figure 7S). 
Table 1S. Proton chemical shifts on the $\beta$-cFapy-dG-dC duplex at $25^{\circ} \mathrm{C}$.

\begin{tabular}{|c|c|c|c|c|c|c|c|c|c|}
\hline & $\mathrm{H} 6 / \mathrm{H} 8$ & H1' & H2" & H2' & H3' & $\mathrm{H} 4{ }^{\prime}$ & $\mathrm{Me} / \mathrm{H} 5 / \mathrm{H} 2$ & $\begin{array}{l}\mathrm{G}(\mathrm{H} 1) / \mathrm{T} \\
(\mathrm{H} 3)\end{array}$ & $\mathrm{CN}_{4} \mathrm{H}$ \\
\hline C1 & 7.59 & 5.74 & 2.39 & 1.98 & 4.66 & 4.03 & 5.85 & & \\
\hline G2 & 7.93 & 5.95 & 2.76 & 2.64 & 4.94 & 4.33 & & 12.81 & \\
\hline (Z)T3 & 7.23 & 5.71 & 2.47 & 2.11 & 4.85 & & 1.48 & 13.50 & \\
\hline (E)T3 & 7.23 & 5.73 & 2.47 & 2.11 & 4.85 & & 1.48 & 13.50 & \\
\hline (Z)A4 & 8.22 & 6.22 & 2.86 & 2.65 & 4.98 & 4.40 & 7.45 & & \\
\hline (E)A4 & 8.22 & 6.21 & 2.86 & 2.64 & 4.97 & 4.40 & 7.42 & & \\
\hline (Z)C5 & 7.35 & 5.90 & 2.37 & 2.10 & 4.80 & & 5.29 & & $8.28 / 6.64$ \\
\hline (E)C5 & 7.27 & 5.89 & 2.30 & 2.00 & 4.76 & & 5.20 & & $8.22 / 6.76$ \\
\hline (Z)F6 & 7.92 & 3.91 & 1.89 & 1.70 & 4.40 & 2.16 & & 12.56 & \\
\hline (E)F6 & 7.21 & 3.83 & 1.90 & 1.72 & 4.41 & 2.17 & & 12.63 & \\
\hline (Z)C7 & 7.50 & 5.91 & 2.53 & 2.14 & 4.87 & 4.23 & 5.65 & & $8.59 / 6.90$ \\
\hline$(E) C 7$ & 7.54 & 5.86 & 2.50 & 2.13 & 4.85 & & 5.69 & & $8.39 / 6.76$ \\
\hline (Z)A8 & 8.23 & 6.20 & 2.65 & 2.89 & 4.97 & 4.35 & 7.59 & & \\
\hline (E)A8 & 8.26 & 6.20 & 2.64 & 2.90 & 4.97 & 4.35 & & & \\
\hline T9 & 7.08 & 5.72 & 2.32 & 1.94 & 4.82 & & 1.37 & 13.57 & \\
\hline G10 & 7.81 & 5.88 & 2.55 & 2.65 & 4.92 & 4.32 & & 12.74 & \\
\hline C11 & 7.38 & 6.13 & 2.13 & 2.16 & 4.44 & 4.01 & 5.33 & & $8.15 / 6.62$ \\
\hline G12 & 789 & 5 & 256 & 274 & 480 & 411 & & 1300 & \\
\hline C13 & 7.42 & 5.66 & 2.12 & 2.44 & 4.85 & 4.17 & 5.39 & & 8.39/6.55 \\
\hline A14 & 8.30 & 6.24 & 2.66 & 2.92 & 4.99 & 4.39 & 7.68 & & \\
\hline T15 & 7.04 & 5.68 & 1.98 & 2.37 & 4.81 & & 1.43 & 13.55 & \\
\hline (Z)G16 & 7.68 & 5.91 & 2.52 & 2.71 & 4.86 & 4.33 & & 12.59 & \\
\hline (E)G16 & 7.69 & 5.87 & 2.52 & 2.67 & 4.88 & 4.33 & & 12.54 & \\
\hline (Z)C17 & 7.12 & 5.57 & 2.03 & 2.32 & 4.64 & 4.07 & 5.24 & & $8.26 / 6.37$ \\
\hline (E)C17 & 7.24 & 5.68 & 2.10 & 2.33 & 4.71 & & 5.28 & & $8.35 / 6.37$ \\
\hline (Z)G18 & 7.53 & 5.84 & 2.65 & 2.47 & 4.75 & 4.24 & & 12.54 & \\
\hline (E) G18 & 7.58 & 5.86 & 2.66 & 2.49 & 4.77 & 4.27 & & 12.53 & \\
\hline (Z)Т19 & 7.30 & 5.78 & 2.48 & 2.11 & 4.86 & & 1.31 & 13.71 & \\
\hline (E)T19 & 7.30 & 5.79 & 2.48 & 2.11 & 4.86 & & 1.31 & 13.71 & \\
\hline (Z)A20 & 8.23 & 6.17 & 2.81 & 2.63 & 4.98 & 4.37 & 7.52 & & \\
\hline (E)A20 & 8.23 & 6.17 & 2.81 & 2.63 & 4.98 & 4.37 & 7.49 & & \\
\hline $\mathrm{C} 21$ & 7.24 & 5.63 & 2.24 & 1.83 & 4.75 & & 5.29 & & $8.27 / 6.74$ \\
\hline G22 & 7.84 & 6.09 & 2.32 & 2.54 & 4.61 & 4.12 & & 13.01 & \\
\hline
\end{tabular}




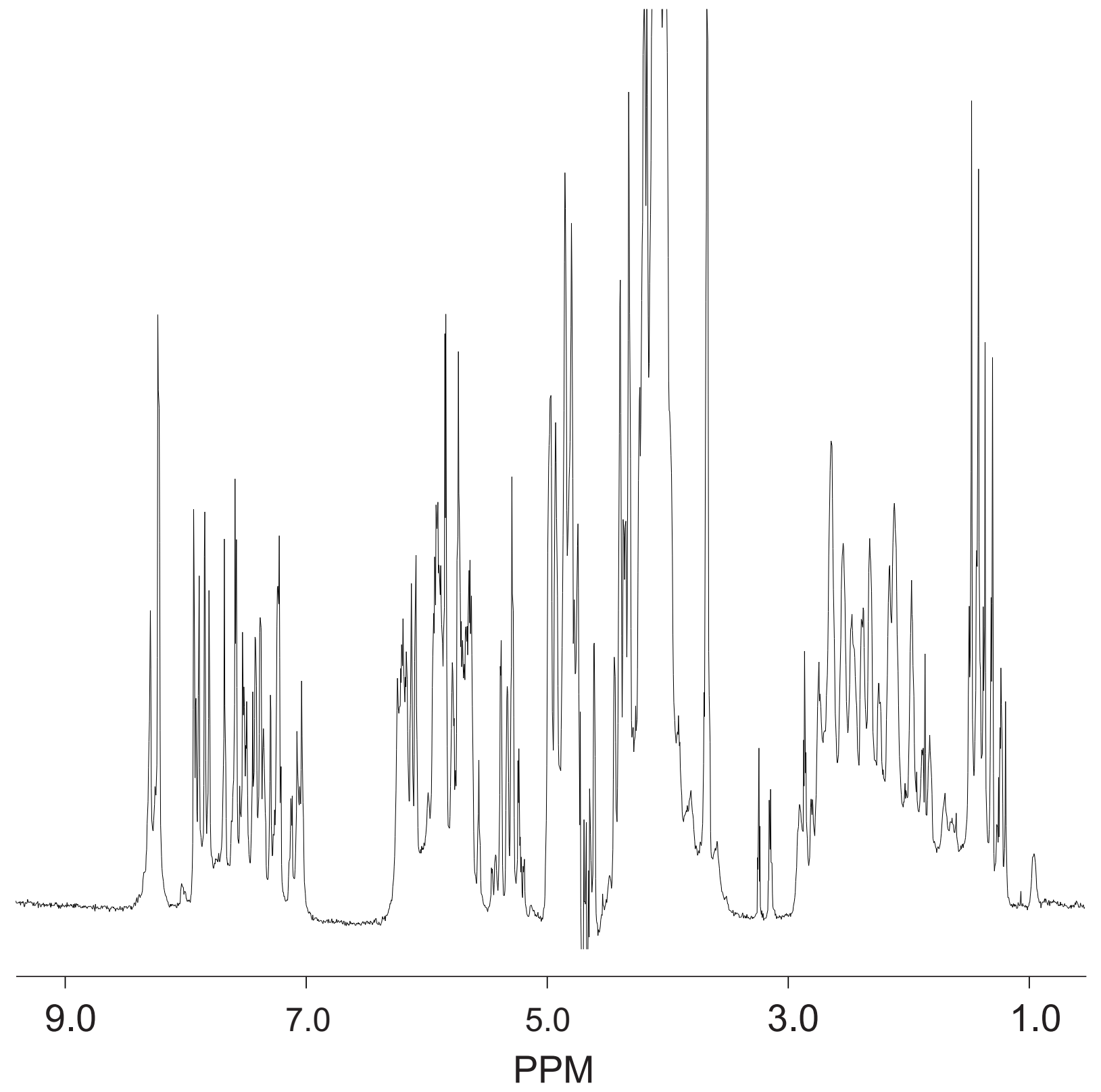

Figure 1S. One dimensional proton spectrum of the cFapy-dG.dC duplex recorded at $600 \mathrm{MHz}$ in $100 \% \mathrm{D}_{2} \mathrm{O}$ buffer, at $25^{\circ} \mathrm{C}$. 


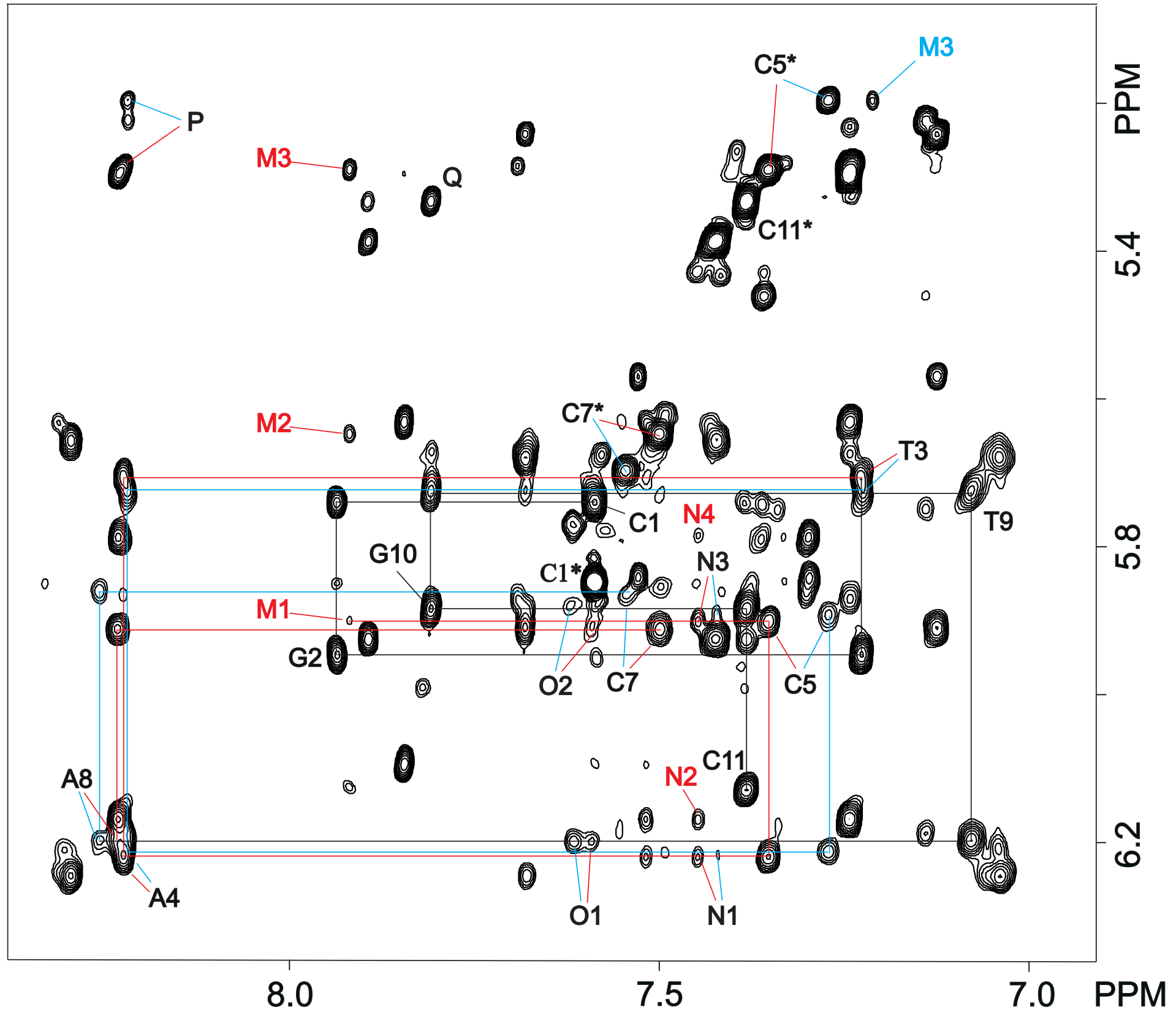

Figure 2SA. Expanded contour plot depicting NOE interactions in the base to $\mathrm{H} 1$ ' proton region of a $800 \mathrm{MHz}$ NOESY spectrum (300 ms. mixing time) recorded in $100 \% \mathrm{D}_{2} \mathrm{O}$ buffer, at $25^{\circ} \mathrm{C}$. Lines connect inter residue and sequential base- $\mathrm{H} 1{ }^{\prime}$ NOE peaks seen in the modified strand of the damaged duplex. Red and blue colors trace these connectivities on the $Z$ and $E$ isomeric duplexes, respectively. Numbered letters label the intra residue NOE, and asterisks indicate cytosine $(\mathrm{H} 5-\mathrm{H} 6)$ peaks. Other labels are assigned as follows: $\mathrm{M} 1, \mathrm{~F} 6 \mathrm{H} 8-\mathrm{C} 5 \mathrm{H} 1$ '; M2, F6H8-C7H5; M3, F6H8-C5H5; N1, A4H2-A4H1'; N2, A4H2-A20-H1'; $\mathrm{N} 3, \mathrm{~A} 4 \mathrm{H} 2-\mathrm{C} 5 \mathrm{H} 1$ '; N4, A4H2-T19H1'; O1, A8H2-A8H1'; O2, A8H2-G16H1'; $\mathrm{P}, \mathrm{A} 4 \mathrm{H} 8-\mathrm{C} 5 \mathrm{H} 5 ; \mathrm{Q}, \mathrm{G} 10 \mathrm{H} 8-\mathrm{C} 11 \mathrm{H} 5$. 


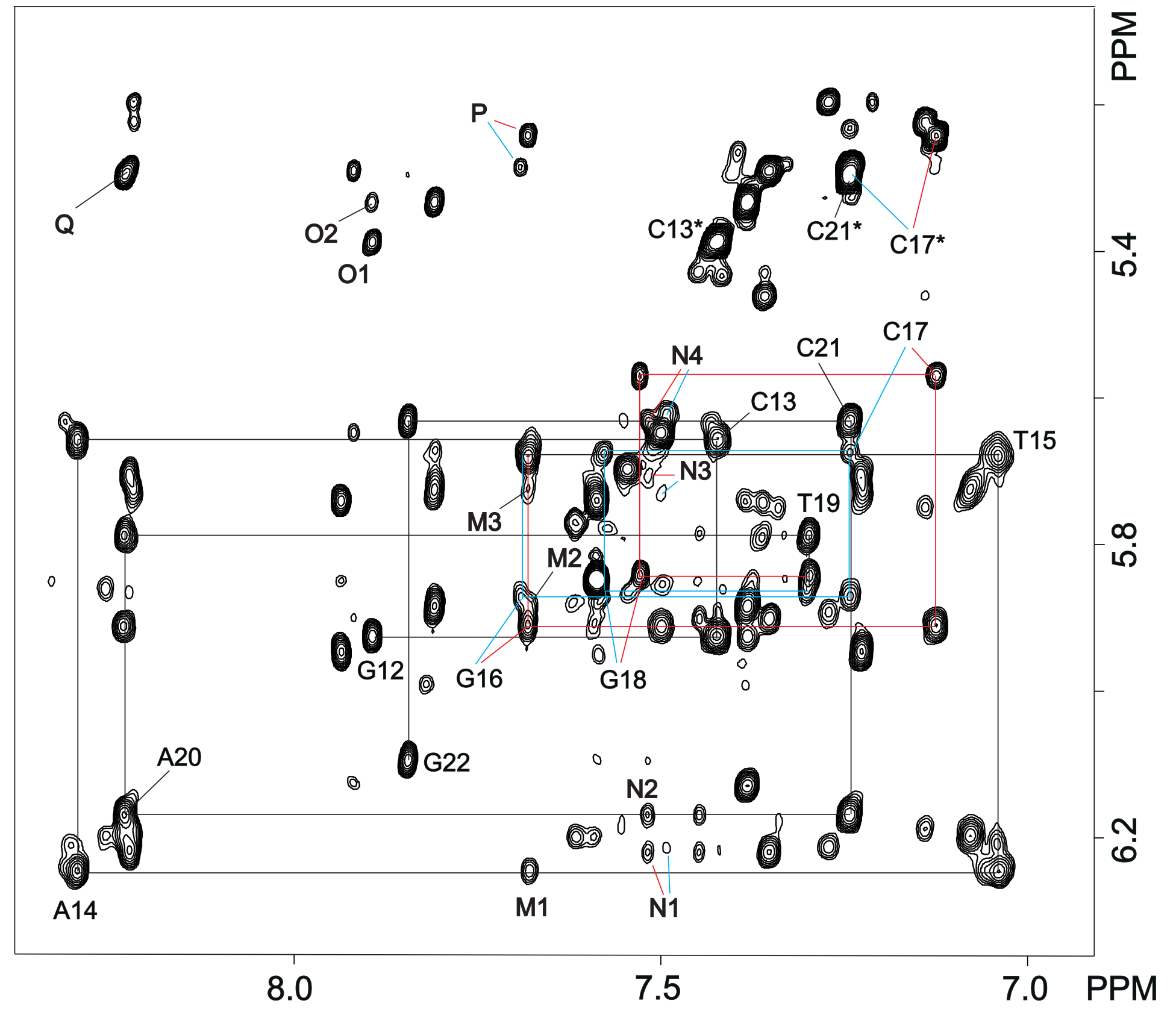

Figure 2SB. Expanded contour plot depicting NOE interactions in the base to $\mathrm{H} 1$ ' proton region of an $800 \mathrm{MHz}$ NOESY spectrum (300 ms. mixing time) recorded in $100 \% \mathrm{D}_{2} \mathrm{O}$ buffer, at $25{ }^{\circ} \mathrm{C}$. Lines connect inter residue and sequential base- $\mathrm{H} 1$ ' NOE peaks seen in the unmodified strand of the damaged duplex. Red and blue colors trace these connectivities in the $Z$ and $E$ isomeric duplexes, respectively. Numbered letters label the intra residue NOE, and asterisks indicate cytosine $(\mathrm{H} 5-\mathrm{H} 6)$ peaks. Other labels are assigned as follows: M1, A14H2-A14H1'; M2, A14H2-G1OH1'; A3, A14H2-T9H1'; N1, A2OH2-A4H1'; N2, A2OH2-A2O-H1'; $\mathrm{N} 3, \mathrm{~A} 2 \mathrm{OH} 2-\mathrm{T} 3 \mathrm{H} 1$ '; N4, A2OH2-C21H1'; O1, G12H8-C13H5; O2, G12H8-C11H5; $\mathrm{P}, \mathrm{G} 16 \mathrm{H} 8-\mathrm{C} 17 \mathrm{H} 5 ; \mathrm{Q}, \mathrm{A} 2 \mathrm{OH} 8-\mathrm{C} 21 \mathrm{H} 5$. 


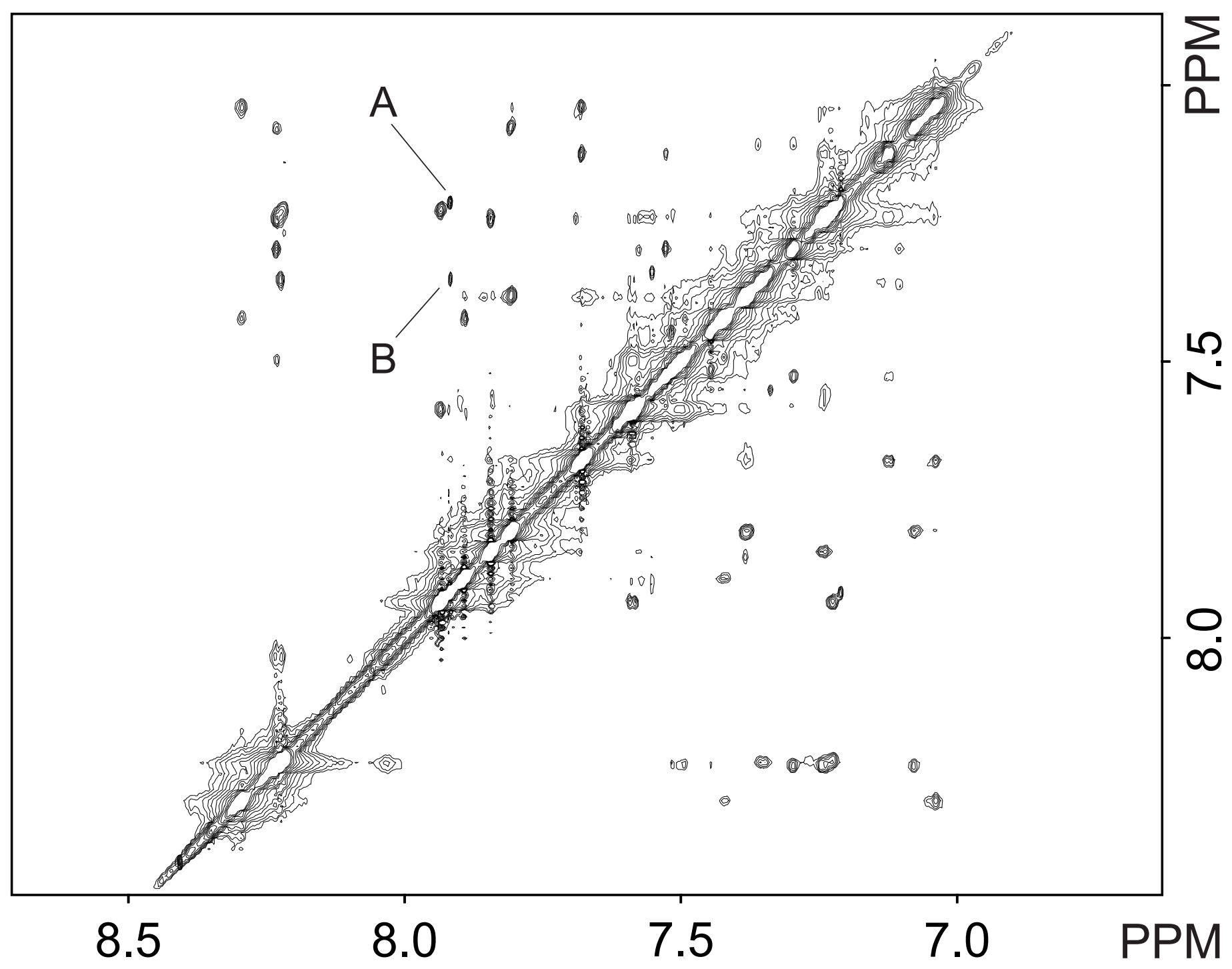

Figure 3S. Expanded contour plot showing the aromatic proton region of an $800 \mathrm{MHZ}$ NOESY spectrum (300 ms. mixing time) recorded in $100 \% \mathrm{D}_{2} \mathrm{O}$ buffer at $25^{\circ} \mathrm{C}$. Labeled peaks are assigned as follows: A, Z-F6(HCO)-E-F6(HCO) exchange cross-peaks; B, Z-F6(HCO)-C5(H6). 


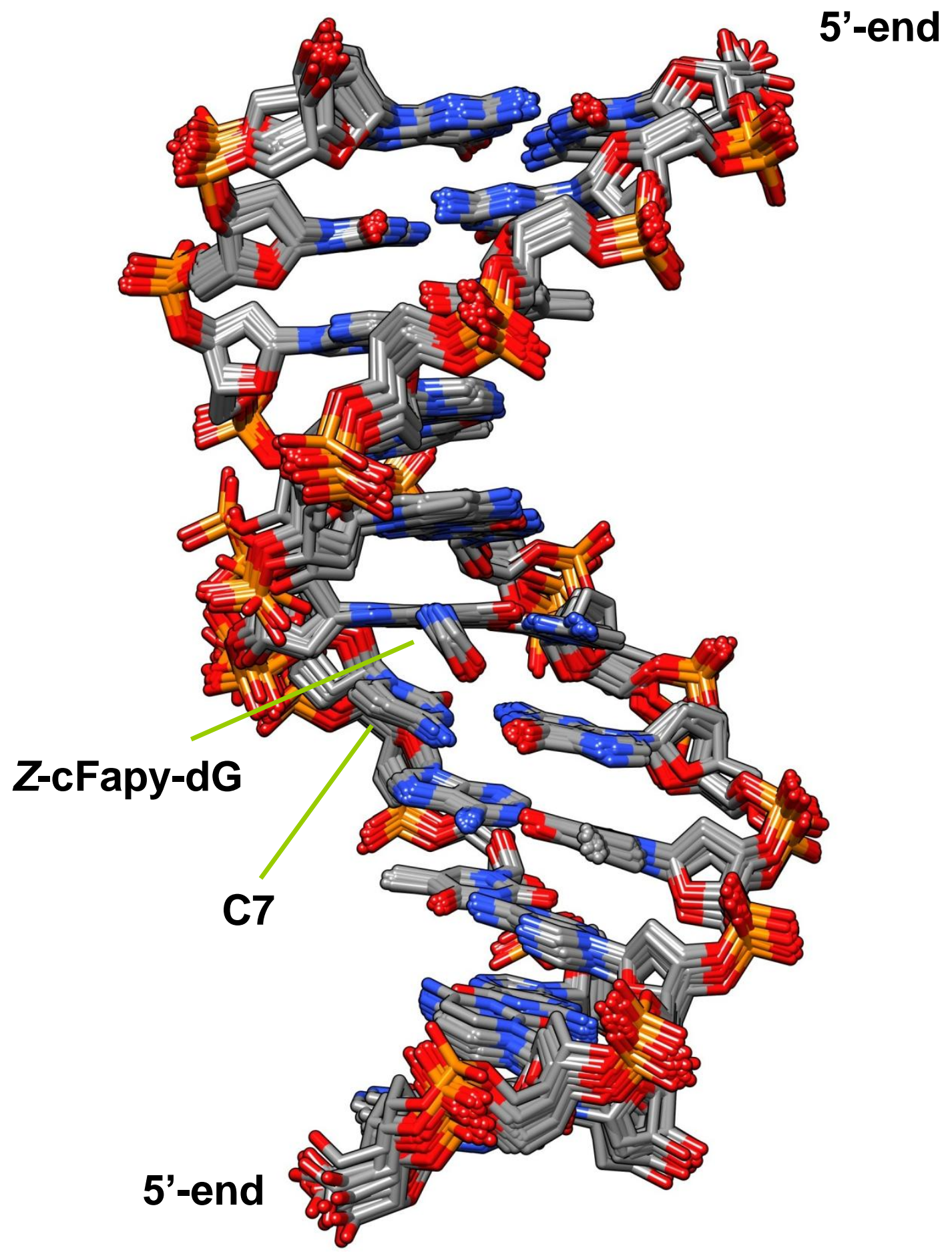

Figure 4S: Superposition of the final 25 structures of the Z-cFapy$\mathrm{dG} \cdot \mathrm{dC}$ duplex seen with the major groove prominent. 


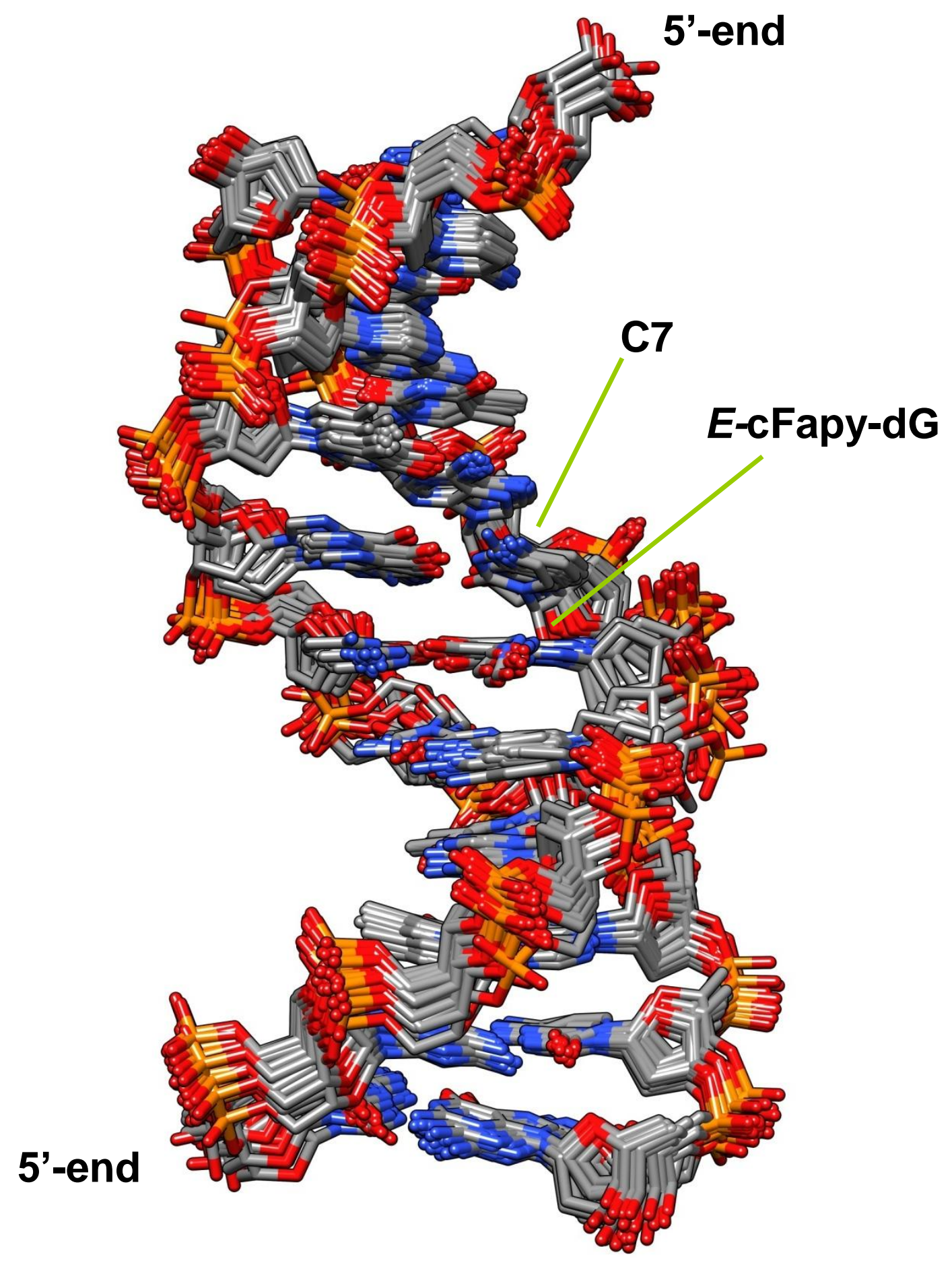

Figure 5S: Superposition of the final 25 structures of the $E$ $c F a p y-d G \cdot d C$ duplex seen with the major groove prominent. 


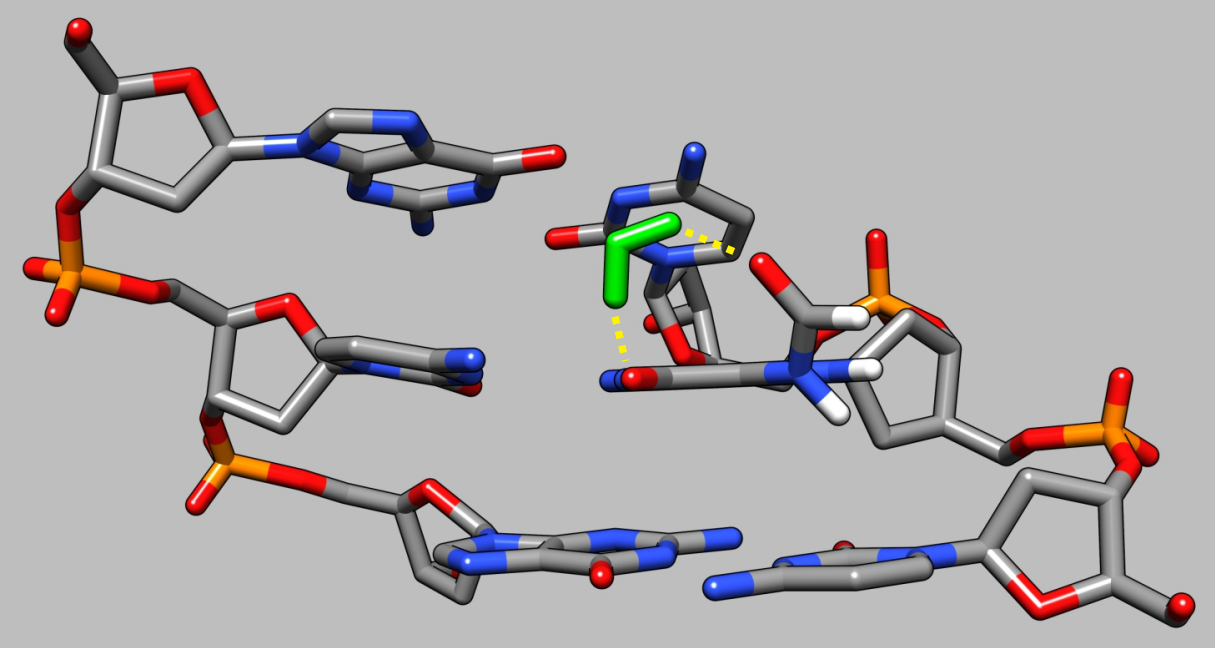

\section{Z-cFapy-dG}

\section{E-cFapy-dG (major form)}

\section{E-cFapy-dG (minor form)}

Figure 6S: Examples of water-mediated hydrogen bonds in the $\beta$-cFapy-dG•dC duplex. Water molecules are colored green. 


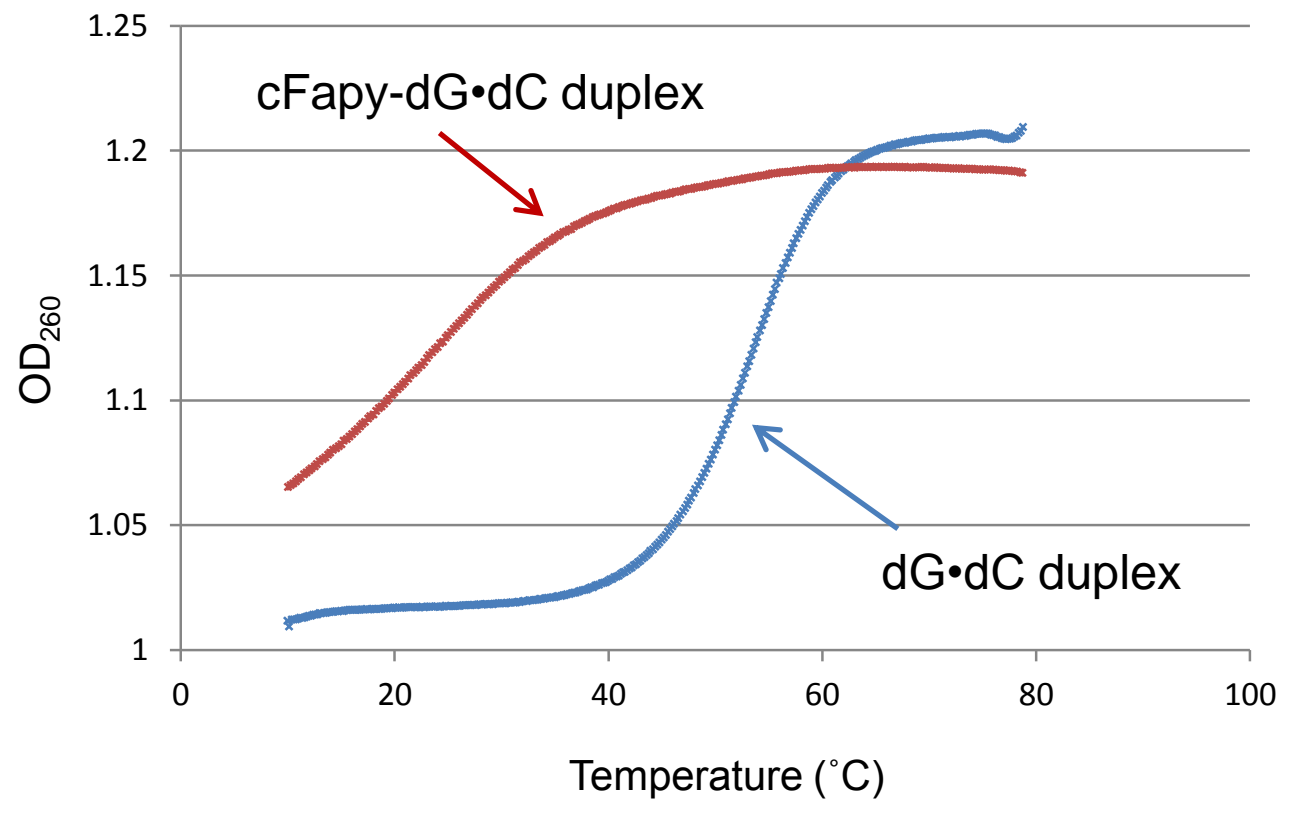

Figure 7S: UV melting profiles of the cFapy-dG・dC and dG・dC duplexes. 